$4^{\text {th }}$ Brazilian Conference on Composite Materials. Rio de Janeiro, July $22^{\text {nd }}-25^{\text {th }}, 2018$

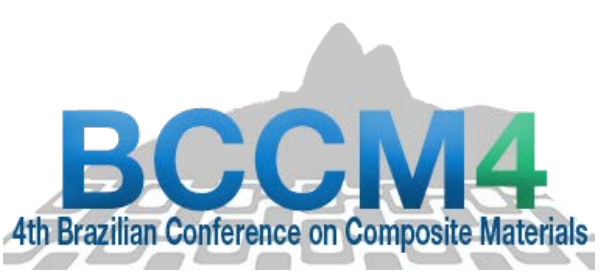

\title{
COMPUTATIONAL ANALYSES FOR CARBON-EPOXY PLATES DAMAGED BY LOW-VELOCITY IMPACT
}

\author{
Gregório Felipe Oliveira Ferreira ${ }^{1}$, Marcelo Leite Ribeiro ${ }^{1}$, António Joaquim Mendes \\ Ferreira $^{2}$, Volnei Tita ${ }^{1}$
}

(1) ${ }^{a}$ Department of Aeronautical Engineering, São Carlos School of Engineering, University of São Paulo, Av. João Dagnone, 1100, 13573-120, São Carlos, SP, Brazil.

(2) Department of Mechanical Engineering, Faculty of Engineering of University of Porto, Rua Dr Roberto Frias s/n, 4200-465, Porto, Portugal.

https://doi.org/10.21452/bccm4.2018.16.01

\begin{abstract}
The usage of composite materials on new design structures is still very conservative, mainly due to its very complex failure behavior. Therefore, the prediction of these mechanisms requires computational analysis. Thus, a damage model based on CDM concepts is applied in order to predict intra-ply failure mechanisms in impacted carbon-epoxy laminate structures. The damage model was implemented as VUMAT (User Material Subroutine for explicit integration analyses) and linked to ABAQUS ${ }^{\mathrm{TM}}$. Several numerical analyses were performed, and the results were compared to experimental tests in order to evaluate the potentialities and limitations of the damage model application.
\end{abstract}

Keywords: composite materials, damage model, progressive failure analyses, low velocity impact, Finite Element Analyses.

\section{INTRODUCTION}

In the last decades, fiber reinforced polymer (FRP) composite materials have aroused great interest within the aircraft and aerospace industry where the design of structures requires optimal stiffness/weight and strength/weight ratio. Composite materials enable the reduction of the structural weight of aircrafts, increasing payload and aircraft range. In spite of the designers' efforts to use composites within the aircraft industry, the application of those materials on civil aircraft structures is still limited due to the certification process and prediction of behavior in service life [1]. Regarding the aircraft life cycle, composite structures are subjected to different impact loads such as airplane ground contact, debris launched from the take-off lane, bird strike, hail and tools that falls during the service and maintenance phase. Based on the investigated literature, composite structures are more susceptible to the impact damage than that similar 
metallic ones. In addition, the dynamic behavior of composite laminates is more complex, considering their anisotropy and heterogeneity which many failure mechanisms occur simultaneously and randomly. The combination of fiber rupture, delamination, matrix fracture, inelastic deformations due to the contact forces and high displacement values can produce catastrophic failure of the structure.

Continuous Damage Mechanics (CDM) is one good approach to formulate intra and interlaminar damage models. This can be confirmed by a list of published works: Abrate [2]; Maio, L. et al. [3]; Zhang et al. [4]; Camanho et al. [5], Shi et al. [6]; Kim et al. [7], Puck \& Shurmann [8]; Feng and Aymerich [9]; Ferreira et al. [10].

Thus, considering the presented scenario, this manuscript shows an application of a new damage model to predict intralaminar failure mechanisms in impacted carbon-epoxy laminate structures. The damage model was implemented as VUMAT (User Material Subroutine for explicit simulations) and linked to ABAQUS ${ }^{\mathrm{TM}}$. After that, several numerical analyses were performed, and the results were compared to experimental tests in order to evaluate the potentialities and limitations of the damage model application.

\section{DAMAGE MODEL: MATHEMATICAL FORMULATION}

The proposed material model is based mainly on the models developed by Ribeiro [11] and Ladevèze \& Le Dantec [12]. Based on CDM concepts, it considers the behavior of fiber and matrix in a meso-mechanical scale (for a homogenized ply) in a plane stress state. Fiber failure under tension and compression, as well as matrix failure under tension, compression and shear are considered in the formulation. Thus, the present model can predict only intralaminar failure, but cannot delamination. Moreover, it was assumed the hypothesis that the failure modes are independents. In this way, matrix failure does not contribute directly to the fiber failure and vice versa. Nevertheless, after failure identification, degradation process of the properties for the failure plies will happen, affecting matrix damage evolution in fiber damage and vice versa. This can be explained through the constitutive matrix modified by damage variables shown by Equation 1 .

$$
D=\frac{1}{K}\left[\begin{array}{ccc}
\left(1-d_{1}\right) E_{11} & \left(1-d_{1}\right)\left(1-d_{2}\right) v_{21} E_{22} & 0 \\
\left(1-d_{1}\right)\left(1-d_{2}\right) v_{21} E_{22} & \left(1-d_{2}\right) E_{22} & 0 \\
0 & 0 & K\left(1-d_{6}\right) G_{12}
\end{array}\right]
$$

with $K=\left[1-\left(1-d_{1}\right)\left(1-d_{2}\right) v_{12} v_{21}\right]$

The behavior of carbon/epoxy laminate under tensile load $\sigma_{11}$ was considered elastic linear and brittle. According to this characteristic, there is not yielding phenomenon, and failure occurs abruptly. Thus, this behavior can be simulated by using the Maximum Stress Criterion, and the internal variable damage $d_{1}$ (related to the degradation in this direction) is considered equal to value " 1 ", when the failure is detected; so it is assumed the complete damage of the reinforcements.

However, in order to model fiber behavior under compression, a linear behavior until a specific value $\mathrm{X}_{\mathrm{C} 0}$ was assumed. When $\sigma_{11} \geq X_{C 0}$, a non-linear elastic behavior was considered. Thus, elastic modulus from $\mathrm{X}_{\mathrm{C} 0}$ is not represented by $E_{11_{0}}$ (initial elastic modulus), but by secant modulus $E_{11}$. Linear tensile, compression and shear limits were considered to simulate the matrix behavior. Those limits were taken from $90^{\circ}$ and $\left[+45^{\circ} /-45^{\circ}\right]$ tests. Based on those results, it was possible to propose a damage surface for the matrix (Figure 1), considering transversal $\left(\sigma_{22}\right)$ and shear stresses $\left(\tau_{12}\right)$. 


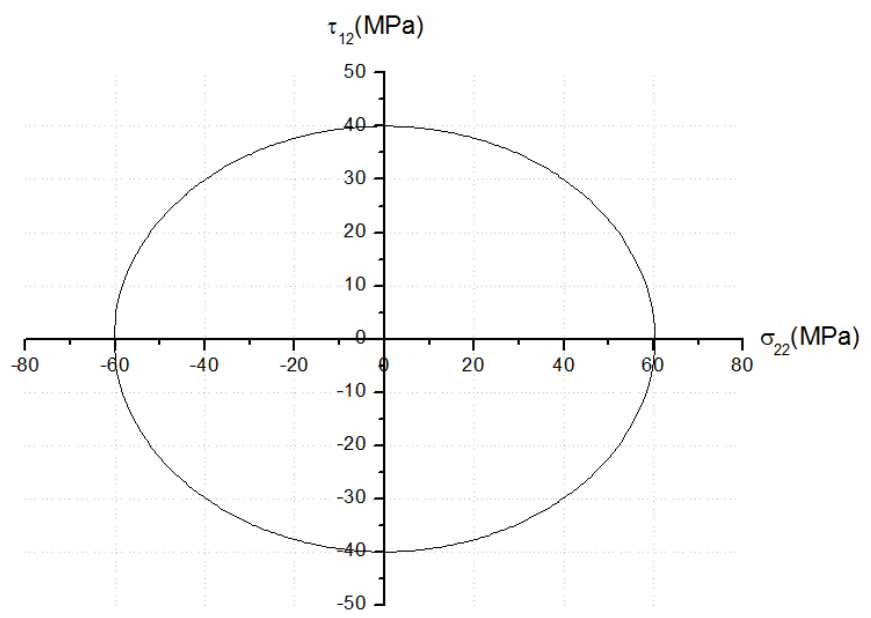

Figure 1- Damage surface for matrix.

The proposed damage surface is represented by Equation 2, and it has as parameters $Y_{C 0}$ and, $S_{12_{Y}}$ both the compression and shear elastic limits.

$$
f=1-\left(\frac{\tau_{12}^{2}}{S_{12_{y}}{ }^{2}}+\frac{\sigma_{22}^{2}}{Y_{c o}^{2}}\right)
$$

The proposed material model is presented in Table 1 and is modified from Ribeiro's [11], since it does not use degradation law as a function of fiber orientation angle. Although it is similar to the model presented by Ladevèze \& Le Dantec [12], it differs totally in fiber and matrix compression behaviors.

Table 1- Proposed material model.

\begin{tabular}{|c|c|c|c|}
\hline $\begin{array}{l}\text { Failure } \\
\text { Criteria }\end{array}$ & Failure Mechanism & Degradation Law & Damage Evolution \\
\hline$\frac{\sigma_{11}}{X_{T}} \geq 1$ & $\begin{array}{l}\text { Fiber failure under } \\
\text { tensile stress }\left(\sigma_{11}>0\right)\end{array}$ & $E_{11}=E_{11_{0}}\left(1-d_{1}\right)$ & \multirow[b]{2}{*}{$d_{1}=1$} \\
\hline$\frac{\left|\sigma_{11}\right|}{X_{C 0}} \geq 1$ & $\begin{array}{l}\text { Fiber failure under } \\
\text { tensile stress }\left(\sigma_{11}<0\right)\end{array}$ & $E_{11}=\frac{X_{C 0}}{\left|\varepsilon_{11}\right|}\left(1-f\left(\varepsilon_{11}\right)\right)+f\left(\varepsilon_{11}\right) \cdot E_{11_{0}}$ & \\
\hline$f \geq 0$ & $\begin{array}{l}\text { Matrix under tensile } \\
\text { stress }\left(\sigma_{22}>0\right)\end{array}$ & $E_{22}=E_{22_{0}}\left(1-d_{2}\right)$ & \multirow{2}{*}{$d_{2}=\frac{\left\langle\sqrt{\hat{\hat{Y}}}-\sqrt{Y_{0}^{\prime}}\right\rangle}{\sqrt{Y_{c}^{\prime}}}$} \\
\hline$f \geq 0$ & $\begin{array}{l}\text { Matrix under tensile } \\
\text { stress }\left(\sigma_{22}<0\right)\end{array}$ & $E_{22}=\frac{Y_{C 0}}{\left|\varepsilon_{22}\right|}\left(1-g\left(\varepsilon_{22}\right)\right)+g\left(\varepsilon_{22}\right) \cdot E_{22_{0}}$ & \\
\hline$f \geq 0$ & $\begin{array}{l}\text { Matrix under shear } \\
\text { stress }\left(\tau_{12}>0\right)\end{array}$ & $G_{12}=G_{12_{0}}\left(1-d_{6}\right)$ & $d_{6}=\frac{\left\langle\sqrt{\underline{\hat{\underline{Y}}}}-\sqrt{Y_{0}}\right\rangle}{\sqrt{Y_{c}}}$ \\
\hline
\end{tabular}

\section{IMPACT TESTS: EXPERIMENTAL AND COMPUTATIONAL ANALYSES}

Impact tests on $120 \mathrm{~mm}$ composite square plates made of prepreg M10 were carried out by Tita et al. [14]. Considering FD (Falling Dart) method [15], the impactor had a hemispheric shape (Figure 1) and is made of aluminum which is added to the frame mass and the load cell. Thus, the total impact mass is around $1.205 \mathrm{~kg}$. Finite Element (FE) models developed in ABAQUS ${ }^{\mathrm{TM}}$ with 
the VUMAT subroutine were used to simulate the carbon-epoxy laminate $\left[+45^{\circ} /-45^{\circ} /+45^{\circ} / 0^{\circ} / 90^{\circ}\right]_{s}$ and $\left[0^{\circ} / 90^{\circ} / 0^{\circ} / 90^{\circ} / 0^{\circ}\right]_{S}$ behavior under impact loading.

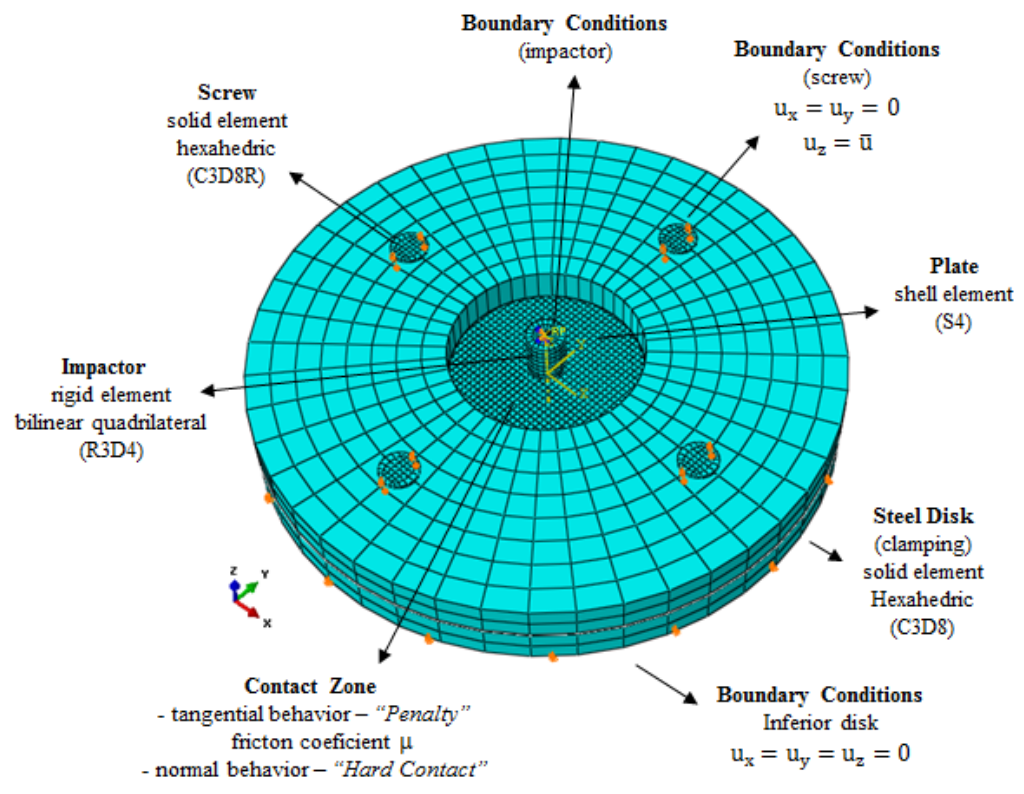

Figure 2- Finite Element model to simulate the impact test

The clamping steel discs and the screws were modeled by full integration eight nodes linear hexahedral solids (C3D8) and reduced integration solid (C3D8R), respectively (Figure 2). The composite plate was modeled by full integration shell elements (S4). Moreover, four nodes quadrilateral rigid bilinear elements (R3D4) were used to simulate the impactor, which has impact mass equal to $1.205 \mathrm{~kg}$ and final velocity of impact around $3.13 \mathrm{~m} / \mathrm{s}$ that corresponds to $5.91 \mathrm{~J}$ of impact energy.

Regarding the boundary conditions used in the FE model, all translations of the bottom disc were restricted $\left(\mathrm{u}_{\mathrm{x}}=\mathrm{u}_{\mathrm{y}}=\mathrm{u}_{\mathrm{z}}=0\right)$, and a prescribed displacement $\left(\mathrm{u}_{\mathrm{z}}=\overline{\mathrm{u}}=1.57 \mathrm{~mm}\right.$ ) equivalent to the torque in-situ was used. The impactor displacement was limited to the $\mathrm{z}$-direction, applying $\mathrm{u}_{\mathrm{x}}=\mathrm{u}_{\mathrm{y}}=0$ and $\mathrm{u}_{\mathrm{z}} \neq 0$. It highlights that the contact between the discs and the composite plate was simulated by using Coulomb Friction Law. Moreover, the contact between the impactor and plate was simulated, considering the tangential penalty algorithm with friction factor equal to 0.15 , and hard contact algorithm for normal behavior.

\section{RESULTS AND DISCUSSION}

First, it was performed mesh convergence tests in order to find "the most adequate" one for the simulations. Different tests of mesh convergence with 3600, 6400 and 14400 elements were handle. Although the mesh with 14000 elements has shown the best response, that with 6400 elements was chosen because of the high computational time simulation of 14400 .

So, from the 6400 elements mesh it was possible to analyze the behavior of the two composite plates under impact. Figure 3-a) shows the force vs. displacement curves for the laminate $\left[+45^{\circ} /-45^{\circ} /+45^{\circ} / 0^{\circ} / 90^{\circ}\right]_{S}$ under $5.91 \mathrm{~J}$ of impact energy. It is possible to observe a high oscillation region between $0.0 \mathrm{~ms}$ and $1.2 \mathrm{~ms}$. At $1.8 \mathrm{~ms}$, there are small oscillations of high frequency. These oscillations are related to the dynamic behavior of the impact event as well as to failure process in 
the composite material. It is important to noteworthy that matrix rupture and delamination drive failure mechanisms as shown by Tita et al. [14], and these mechanisms reduce the structure global stiffness. However, the maximum force value provided by the numerical analyses with damage model $(3313.39 \mathrm{~N})$ is closer to the maximum experimental force $(3217.77 \mathrm{~N})$ than without damage $(3470.37 \mathrm{~N})$. Besides, the duration of the impact event was around $4.0 \mathrm{~ms}$ for the experimental test, and numerical analysis with damage model predicted $3.7 \mathrm{~ms}$, which was very close to the value provided by FE analysis without damage model (3.6 ms).

In the Figure 3-b), the FE model simulated about $50 \%$ of the absorbed energy by the real structure $(2.0 \mathrm{~J})$. It is important to observe that the absorbed energy predicted by the FE model is entire related to matrix damage mechanism, which is shown by the damage parameters $\mathrm{d}_{2}$ and $\mathrm{d}_{6}$.

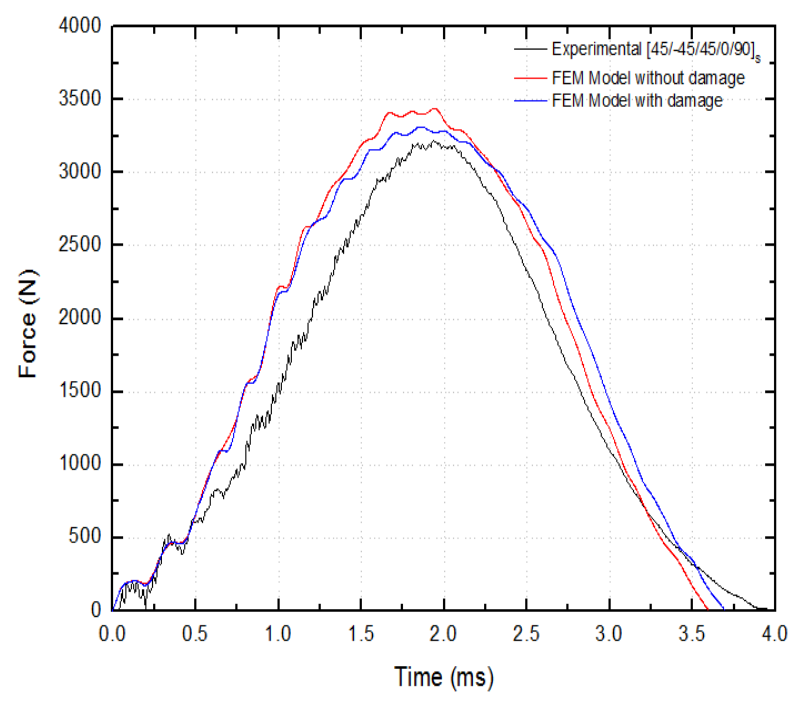

a)

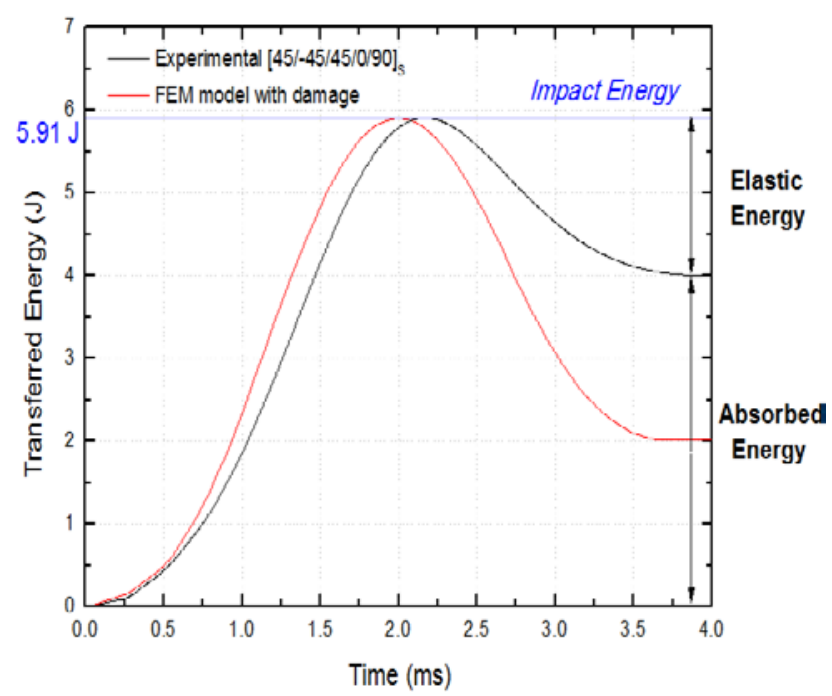

b)

Figure 3- Comparison between experimental and numerical results for the $\left[+45^{\circ} /-45^{\circ} /+45^{\circ} / 0^{\circ} / 90^{\circ}\right]_{S}$ laminate under 5.91 J. a) Force x time b) Energy transferred vs. time

In other hand, from Figure 4-a), it is observed qualitatively, that the damage variable $\mathrm{d}_{2}$ was activated until the $6^{\text {th }}$ layer, which is oriented at $90^{\circ}$, while $\mathrm{d}_{6}$ showed a discontinuity in the $7^{\text {th }}$ layer, but it is verified in $8^{\text {th }}, 9^{\text {th }}$ and $10^{\text {th }}$ layers. The damage evolution along the laminate thickness close to the impact point is represented by the Figure 4-b). At the final of $5.91 \mathrm{~J}$ impact event, the damage caused in the matrix due to shear stress in $2^{\text {nd }}$ and $4^{\text {th }}$ layers was complete, i.e. $d_{6}=1$. For the $8^{\text {th }}, 9^{\text {th }}$ and $10^{\text {th }}$ layers, the damage is caused by shear stress, and the parameter $d_{6}$ is respectively equal to $0.0001,0.08$ and 0.18 . However, the parameter $\mathrm{d}_{2}$ associated to tensile transversal stress on matrix reaches the maximum in first three layers. It is verified that there is no damage in matrix caused by tensile transversal stress from $7^{\text {th }}$ until $10^{\text {th }}$ layers, once the parameter $\mathrm{d}_{2}$ is equal " 0 " $f o r$ those layers. 

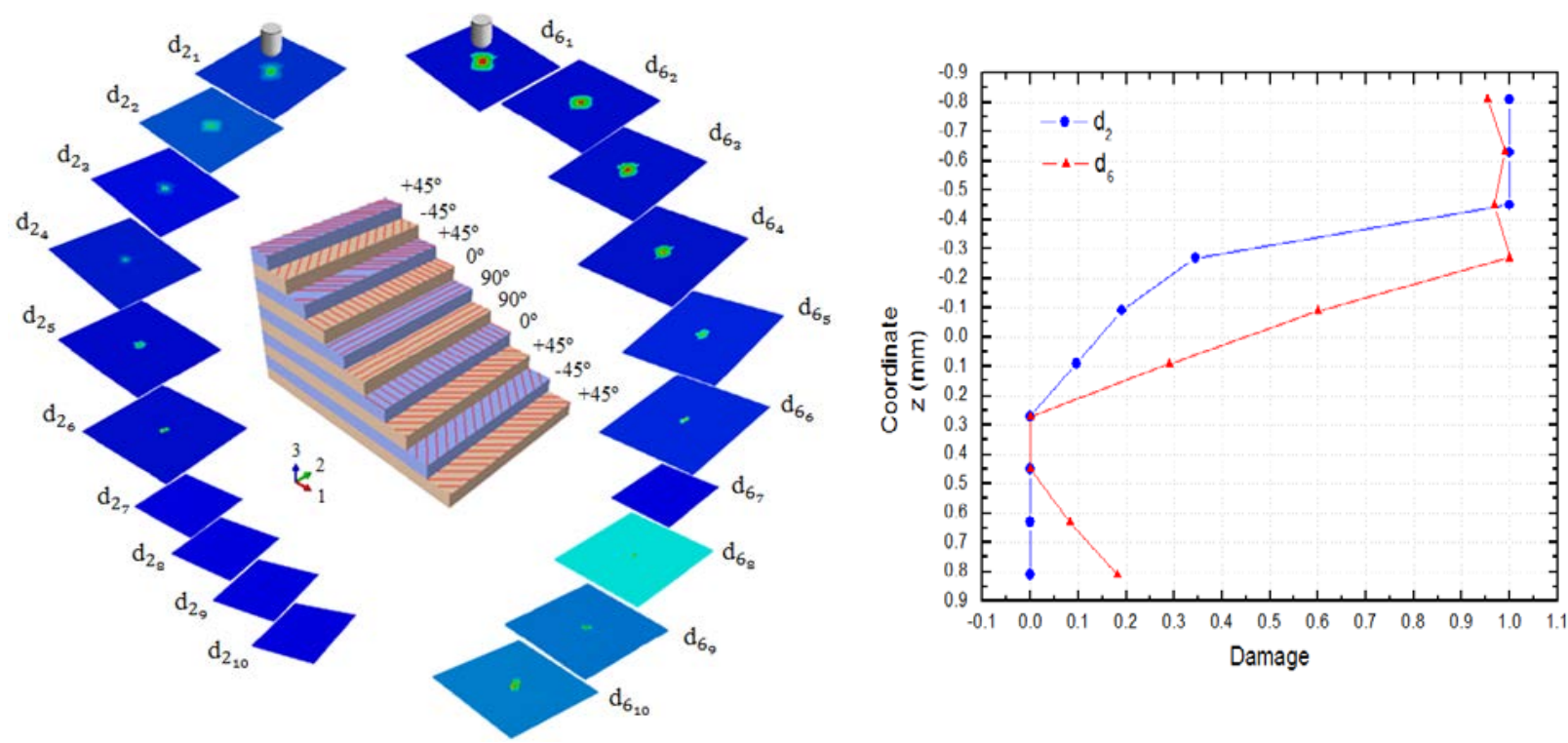

Figure 4- Qualitative and quantitative analysis for the laminate $\left[+45^{\circ} /-45^{\circ} /+45^{\circ} / 0^{\circ} / 90^{\circ}\right]_{S}$ at the final of impact event.

a) Damage variables $d_{2}$ and $d_{6}$ for the layers of laminate b) Damage evolution along the laminate thickness

Figure 5-a) shows the force vs. time curve for the laminate $\left[0^{\circ} / 90^{\circ} / 0^{\circ} / 90^{\circ} / 0^{\circ}\right]_{s}$ under $5.91 \mathrm{~J}$ of impact energy. In the experimental results, a high frequency oscillation region between $0.0 \mathrm{~ms}$ and $1.2 \mathrm{~ms}$ can be observed. In this laminate, the main failure mechanisms are matrix rupture and delamination, which reduce the global structural stiffness, as well. FE analysis using the proposed damage model was able to simulate the impact high frequency oscillations from $0.0 \mathrm{~ms}$ until 0.25 $\mathrm{ms}$ and between $0.75 \mathrm{~ms}$ and $1.25 \mathrm{~ms}$. On the other hand, the FE analysis using only the elastic model was able to simulate the oscillations beginning from $0.0 \mathrm{~ms}$ until $0.25 \mathrm{~ms}$ and the maximum force equal to $3072.81 \mathrm{~N}$. However, it is observed that the maximum force simulated by using the damage model was equal to $2847.63 \mathrm{~N}$, which was lower than the force predicted by elastic model. Moreover, in the Figure 5-a), it is observed that after $2.0 \mathrm{~ms}$, FE analysis with damage model (blue curve) diverges of the experimental curve, while FE analysis with elastic model (red curve) approaches to the experimental result (black curve). This was expected due to the absence of a delamination model to simulate the separation between $0^{\circ}$ and $90^{\circ}$ layers. From Figure 5-b), FE analyses with damage model predicted about $50 \%$ of the absorbed energy by the cross ply laminate sample, i.e. about $1.98 \mathrm{~J}$. Thus, the absorbed energy predicted by FE analysis was totally related to the matrix damage mechanism. This can be verified in the Figure 6-a) monitoring the damage parameters $d_{2}$ and $d_{6}$. The damage variable $d_{2}$ was activated from the $1^{\text {st }}$ layer until the $5^{\text {th }}$ layer, while for the damage variable $d_{6}$, the damage is verified not only from the $1^{\text {st }}$ layer until the $5^{\text {th }}$ layer, but also in $8^{\text {th }}, 9^{\text {th }}$ and $10^{\text {th }}$ layers. By the Figure 6-b), it is shown the damage evolution along the laminate thickness close to the impact point. The damage caused by the shear stresses in the matrix was relevant as confirmed by the damage parameter $d_{6}$, which was close to " 1 " in the first three layers. Moreover, it was verified the damage caused by transversal tensile stresses in the matrix reached the maximum value (" 1 ”) only in the $1^{\text {st }}$ layer. It is observed that from the $6^{\text {th }}$ layer, there was not damage caused by transversal tensile stress in the matrix, only damage caused by shear stress. And, the values of $d_{6}$ are $0.1,0.15$ and 0.2 for the $8^{\text {th }}, 9^{\text {th }}$ and $10^{\text {th }}$ layers, respectively. 


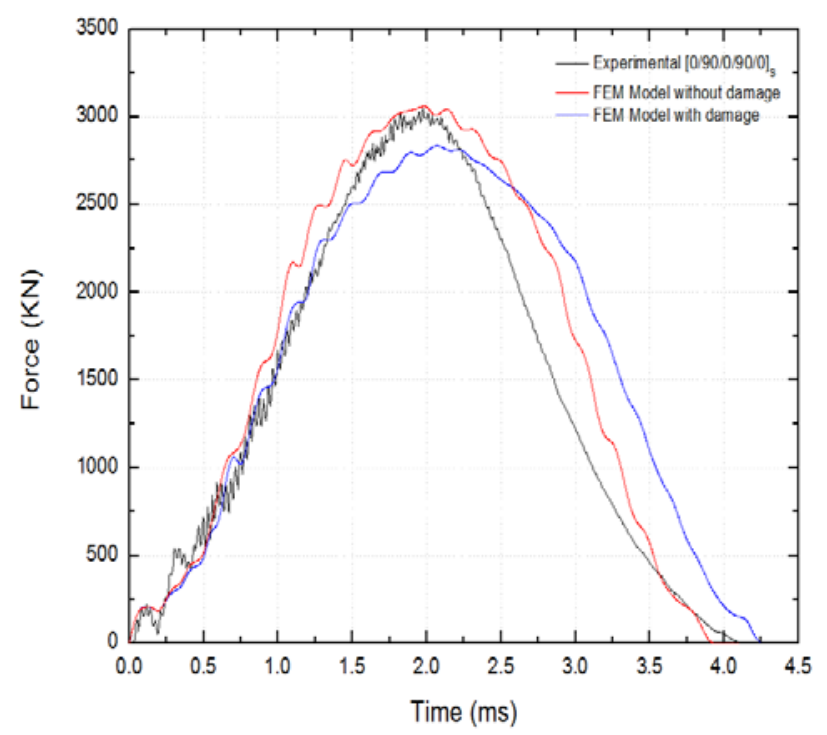

a)

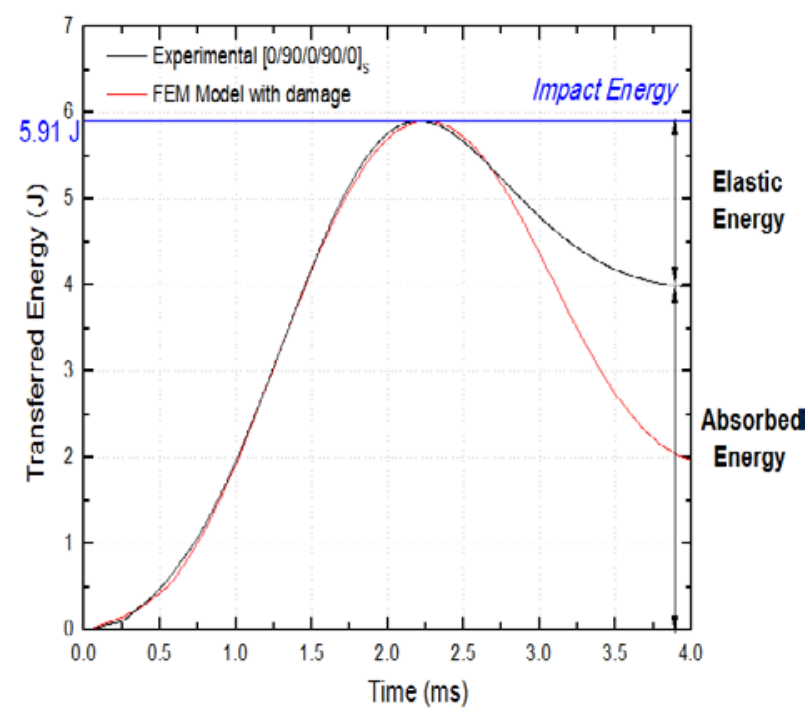

b)

Figure 5- Comparison between experimental and numerical results for the $\left[0^{\circ} / 90^{\circ} / 0^{\circ} / 90^{\circ} / 0^{\circ}\right]_{S}$ laminate. a) Force $\mathrm{x}$ time b) Energy transferred vs. time
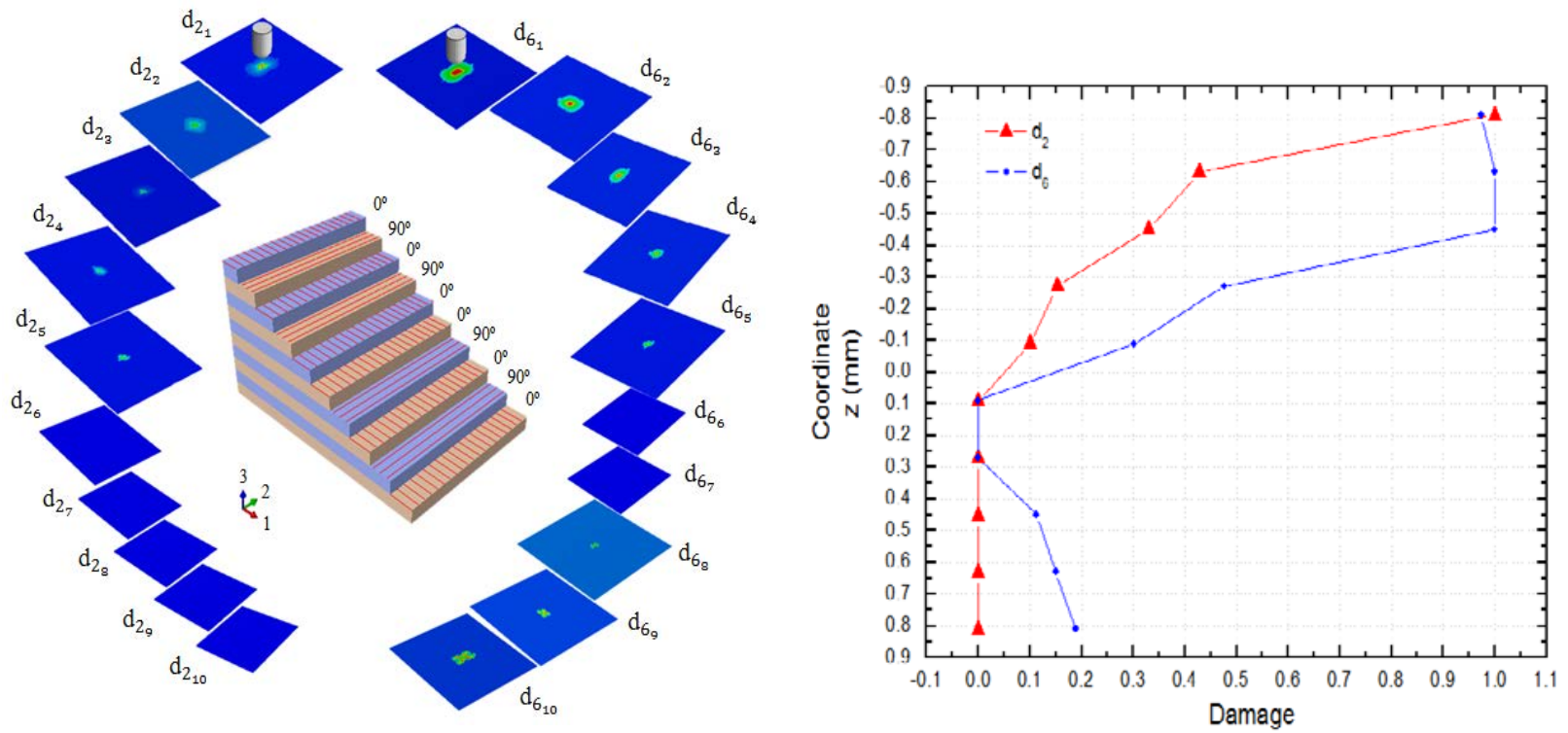

Figure 6- Qualitative and quantitative analysis of laminate $\left[0^{\circ} / 90^{\circ} / 0^{\circ} / 90^{\circ} / 0^{\circ}\right]_{s}$ at the final of impact event. a) Damage variables $d_{2}$ and $d_{6}$ for the layers of laminate b) Damage evolution along the laminate thickness

\section{$5 \quad$ CONCLUSIONS}

A new damage model was applied for simulating impact problems on composite structures. This damage model was implemented as an explicit subroutine (VUMAT) and linked to software ABAQUS $^{\mathrm{TM}}$. Thus, based on the implemented damage model, intra-ply failure mechanisms in carbon-epoxy plates were investigated considering low velocity impact load for two different laminate configurations. Due to the proposed formulation, including damage evolution laws, as well as the strategy for implementation, the FE analyses were performed with a reasonable computational cost and no convergence problems occurred during simulations. Moreover, 
$4^{\text {th }}$ Brazilian Conference on Composite Materials. Rio de Janeiro, July $22^{\text {nd }}-25^{\text {th }}, 2018$

acceptable results for Force vs. time are showed in the simulation, although delamination phenomenon was not considered in the analyses. The simulation of delamination process requires a much more complicated and complex model, generating numerical issues such as high computational cost and convergence problems.

Therefore, the present computational analyses can provide an alternative way in order to obtain good predictions of Force vs. time graphics with low computational cost, which can help conceptual and preliminary design of composite structures under impact loadings.

\section{Acknowledgements}

The authors acknowledge the financial support of the Coordination for the Improvement of the Higher Level Personnel (CAPES/PROEX) and National Council for Scientific and Technological Development (CNPq process numbers: 401170/2014-4 and 310094/2015-1). Volnei Tita acknowledges the financial support of Air Force Office of Scientific Research - AFOSR (Grant FA9550-16-1-0222).

\section{REFERENCES}

[1] Zhou, W. X.; Gao, X., Damage and failure of a laminated carbon fiber reinforced composite under low velocity impact, Journal of Aerospace Engineering 27: 308-317, 2012.

[2] Abrate, S. Modeling of impacts on composite structures, Composite Structures 51: 129-138. 2001.

[3] Maio, L., Monaco, E., Ricci, F., Lecce. L., Simulation of low velocity impact on composite laminates with progressive failure analysis, Composite Structures 103: 75-85, 2013.

[4] Zhang, Yan; Zhu, Ping; Lai, Xinmin. Finite element analysis of low-velocity impact damage in composite laminated plates, Materials \& Design. 27, 513-519, 2006.

[5] Camanho PP, Miamí P, Dávila CG. Prediction of size effects in notched laminates using continuum damage mechanics. Compos Sci Technol; 67 (13):2715-27, 2007.

[6] Shi, Y., Swait, T., Soutis, C., Modelling damage evolution in composite laminates subjected to low velocity impact, Composite Structures 94:2902-2913, 2012.

[7] Kim, E., Rim, M., Lee, I., Hwang, T., Composite damage model based on continuum damage mechanics and low velocity impact analysis of composite plates, Composite Structures 95: 123-124, 2013.

[8] Puck, A.; Schürmann, H., Failure analysis of FRP laminates by means of physically based phenomenological models, Composites Science and Technology 62: 1633-1662, 2002.

[9] Feng, D., Aymerich, F., Finite element modelling of damage induced by low-velocity impact on composite laminates, Composite Structures 108: 161-171, 2014.

[10] Ferreira, G.F.O., Medeiros, R.M., Ogea, J.L., Tita, V. Damage simulation in composite structures considering friction and sliding effect. In Fifth International Symposium on Solid Mechanics MECSOL2015, Belo Horizonte, Brazil. Proceedings of MECSOL, 2015.

[11] Ribeiro M.L.; Tita V.; Vandepitte D., A new damage model for composite laminates, Composite Structures 94: 635-642, 2012.

[12] Ladevèze, P.; Le Dantec, E., Damage modelling of the elementary ply for laminated composites, Composites Science and Technology 43: 257-267, 1996.

[13] Matzenmiller A, Lubliner J, Taylor RL. A constitutive model for anisotropic damage in fibercomposites. Mech Mater; 20 (2):125-52, 1995.

[14] Tita, V., Carvalho, J., Vandepitte, D., Failure analysis of low velocity impact on thin composite laminates: experimental and numerical approaches, Composite Structures 83: 413-428, 2008.

[15] American Society for Testing and Materials. ASTM D5628-96. Standart test method for impact of flat, rigid plastic specimens by means of falling dart (Tup or falling mass). West Conshoken, 2001. 